\title{
Physics of the Frequency Response of Rectifying Organic Schottky Diodes
}

\author{
${ }^{\mathrm{a}, \mathrm{b}}$ Stéphane Altazin*, ${ }^{\mathrm{c}}$ Raphaël Clerc, ${ }^{\mathrm{a}}$ Romain Gwoziecki, ${ }^{\mathrm{a} J e a n-M a r i e ~ V e r i l h a c, ~}$ \\ ${ }^{\mathrm{a}}$ Damien Boudinet, ${ }^{\mathrm{b}}$ Georges Pananakakis, ${ }^{\mathrm{b}}$ Gérard Ghibaudo, ${ }^{\mathrm{a}}$ Isabelle Chartier \\ and ${ }^{\mathrm{a}}$ Romain Coppard
}

${ }^{\mathrm{a}}$ CEA/LITEN/LCI, 38054 Grenoble (France)

${ }^{\mathrm{b}}$ IMEP-LAHC, Minatec Grenoble INP, Grenoble, France.

* Now with Fluxim AG, Technoparkstrasse 2, CH-8406 Winterthur, Switzerland

c Laboratoire Hubert Curien (UMR 5516 CNRS), Université Jean Monnet, Institut d'Optique Graduate School,18 rue Benoît Lauras 42000, Saint-Etienne, France.

Corresponding author : (raphael.clerc@institutoptique.fr)

Keywords: Organic Schottky diode, RFID Tag, rectifying circuit, Frequency, time dependent response, modeling) 


\section{$\underline{\text { Abstract }}$}

The frequency response of unipolar organic Schottky diodes used in a rectifying circuit, such as an RFID tag, has been investigated in detail. The time dependent response of rectifying circuits has been simulated solving both the Drift Diffusion and Poisson equations to model the hole transport within the diode, coupled with time dependent circuit equations. Several approximations have also been discussed. It turns out that the cut off frequency of the rectifying circuit is indeed limited by the carrier time-of-flight, and not by the diode equivalent capacitance. Simulations have also been confirmed by comparison with experiments, involving diodes with different mobilities and thicknesses. This work confirms that the $13.56 \mathrm{MHz}$ frequency can be reached using polymer semiconductors, as already experimentally demonstrated in the literature, by an adequate control of the active layer thickness. 


\section{Introduction}

One of the most promising applications of organic electronics consists in the production of low cost radio frequency identification (RFID) tags on flexible substrates [1 - 3]. Several research groups have already published encouraging results on organic devices, building blocks and complete systems for RFID applications [1 - 15]. Among the most striking realizations, the world first "roll-to -roll” organic RFID tag (a 64-bit tag working at a bit rate exceeding $100 \mathrm{~b} / \mathrm{s}$, readout by inductive coupling at a base carrier frequency of $13.56 \mathrm{MHz}$ ) was presented in 2006 by Poly IC [1, 3]. More recently, full organic RFID tags for barcode replacement, generating code sequences up to 128 bits, have been demonstrated operating at the frequency communication frequency of $13.56 \mathrm{MHz}$ [7 - 8]. In the latter case, the substrate, a PEN foil, was laminated on a rigid wafer and processed using standard semiconductor equipment. In particular, the organic semiconductor (pentacene) was evaporated in an ultra-high vacuum chamber.

One of the challenges of full organic RFID tags consists in achieving a rectifying diode operating at frequency equal to or even higher than $13.56 \mathrm{MHz}$, using an organic semiconductor, materials which are known to be penalized by their relatively poor transport properties. That is why the most common procedure to manufacture these diodes is to evaporate small molecules semiconductors (such as pentacene [4 - 10], copper phthalocyanine ( $\mathrm{CuPc}$ ) [11] or C60 [12]). Indeed, this technique is known to be appropriate for growing high mobility polycrystalline layers (of the order of 0.15 $\mathrm{cm}^{2} \mathrm{~V}^{-1} \mathrm{~s}^{-1}$, such as for the pentacene used in [5]). To realize rectifying devices, these semiconductors can then be introduced either in Schottky diodes [5 - 12], or diodes connected organic transistors [13 - 14]. However, the evaporation deposition process may not be compatible with the requirements of low cost roll-to-roll or printing technology.

Moreover, alternative solutions to evaporated small molecules, such as conjugate polymers, are known to feature significantly lower mobilities (the best value being in the range of $\sim 0.01 \mathrm{~cm}^{2} \mathrm{~V}^{-1} \mathrm{~s}^{-}$ $\left.{ }^{1}\right)$. In spite of that fact, there are several examples in the literature of successful polymer based rectifying diodes operating at frequency higher than $13.56 \mathrm{MHz}[1,3,4,15$ - 17]. The success of 
these rectifying polymer diodes thus raises the following questions: is the mobility the only limiting factor of the operating frequency of organic rectifying diodes? What are the device requirements needed to achieve such frequency limit?

A literature search reveals that these questions have not been solved yet. The mechanisms limiting the frequency operation of organic Schottky diodes in rectifying circuits do not appear to be well understood, and in many aspects even controversial. Indeed, several articles attribute the time limitation of rectifying circuits to the carrier time-of-flight within the diode $[15,17]$, but without providing any convincing proof. That statement has been questioned in [5], proposing an improved formula, presented as a "more stringent and realistic frequency limit". Instead, other authors [11, 12] blame the diode equivalent capacitance, supposed to shunt the diode equivalent conductance at high frequencies [11].

This controversial situation regarding the limiting frequency of organic Schottky diode is not so surprising. Indeed, first of all, organic Schottky diodes essentially operate in a different way compared to conventional inorganic junction, and are not completely understood yet. Moreover, the rectification is intrinsically a highly non linear process, which cannot be described by the conventional linear small signal approaches to analyze circuits. For those reasons, the frequency response of those devices is a non trivial issue.

The aim of this work is to investigate in detail the physics of the organic Schottky diode frequency response, and to determine the key parameters impacting it. First of all, our approach relies on an accurate time dependent modeling of both the organic Schottky diode and the rectifying circuit, by the means of numerical and analytical calculations. Theoretical results are then compared in details with experiments, performed on home made printed diodes, operating at larger frequency than $13.56 \mathrm{MHz}$.

The present article is organized as follows: devices that have been fabricated and characterized are presented in the first section. Then, three different approaches to model the organic diode within 
non linear circuit background are presented and compared. Models and experiments are then compared in the final section. 


\section{Device fabrication and characterization}

In order to characterize the frequency operation of rectifying circuits, conventional organic rectifying diodes have been fabricated, using a process compatible with the requirement of printed electronics, and presented in the following section.

(a)

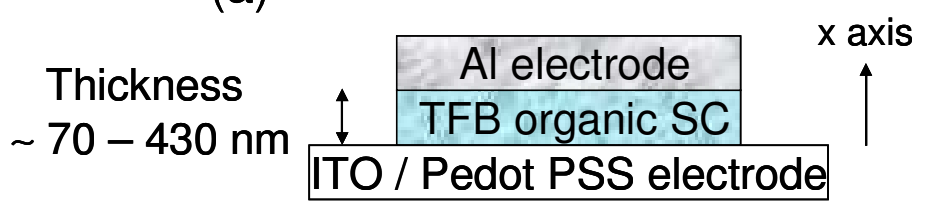

(b) Organic diode

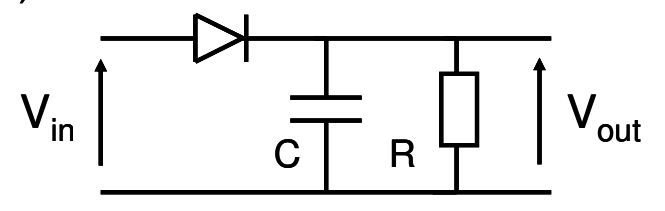

Figure 1. Schematic view of the diode used in this article (a) and schematic view of a rectifying circuit studied in this article (b)

\subsection{Organic diode process}

Substrate is composed of a $100 \mathrm{~nm}$ layer of ITO deposited on glass, and then patterned. Then, a 50nm thin layer of gold is deposited to contact ITO with an external tips. PEDOT:PSS layer was introduced in order to improve the hole injection. Then, the organic semiconductor (poly(fluorenealt-triarylamine) TFB in our case, see reference [18] for details), has been deposited by spin coating at different rotation speeds, in order to get different thicknesses L. These thicknesses, measured by a profilometer are $70 \mathrm{~nm}, 260 \mathrm{~nm}$ and $430 \mathrm{~nm}$. Then the device has been baked at $100^{\circ} \mathrm{C}$ during one minute. $200 \mathrm{~nm}$ of Aluminium has been deposited through a shadow mask, to realise the top contact. Finally, devices have been encapsulated by sticking, on its top, a glass plate. The substrate used in the device measured here is composed of glass, but similar results can be obtained using flexible substrate such as PEN. The schematic view of these diodes is presented in figure 1. 


\subsection{Electrical measurements}

The static I-V characteristics of organic diodes have been measured by conventional high resolution semiconductor analyser. Then, these devices have been introduced in the basic rectifying circuit illustrated in figure 1 . The capability of these diodes to perform a rectifying operation has been demonstrated, as shown in figure 2, applying an input sinusoidal signal $\mathrm{V}_{\mathrm{in}}$, and measuring the ouput signal $\mathrm{V}_{\text {out }}$. If the rectifying operation has been successful, as it can been seen in figure 2 , performed at $15 \mathrm{MHz}$, the ouput voltage $\mathrm{V}_{\text {out }}$ should be nearly a constant signal.

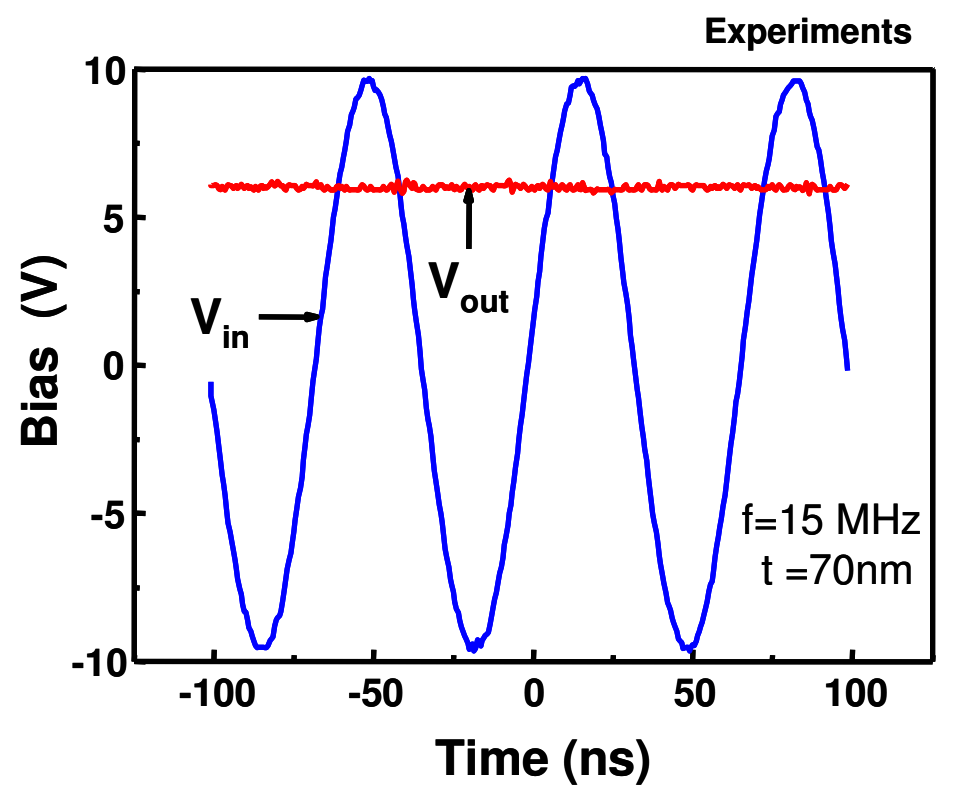

Figure 2. Experimental $\mathrm{V}_{\text {in }}$ and $\mathrm{V}_{\text {out }}$ signals versus time, illustrating the successful operation of the rectifying circuit at $15 \mathrm{MHz}$. This circuit is composed of a TFB diode of thickness $70 \mathrm{~nm}$ and area S $=210^{-7} \mathrm{~m}^{2}$, a resistance of $\mathrm{R}=1 \mathrm{M} \Omega$, and a capacitor of $\mathrm{C}=1 \mu \mathrm{F}$. 


\section{Modeling of rectifying elementary circuit}

In order to investigate the physics of the frequency operation of a Schottky diode in a rectifying circuit, the operation of the full circuit, including the operation of the diode and the circuit, has to be considered. Such a rigorous approach has been implemented and described in the first section. It consists in a "mixed mode" approach, where Physics based equations are solved versus time, for both the diode itself and the full circuit. Simplified approaches are also discussed in the following sections. In particular, an original approach is proposed in the final section, saving computational time, without any significant accuracy loss. Different approaches investigated in this work are schematized in figure 3 .

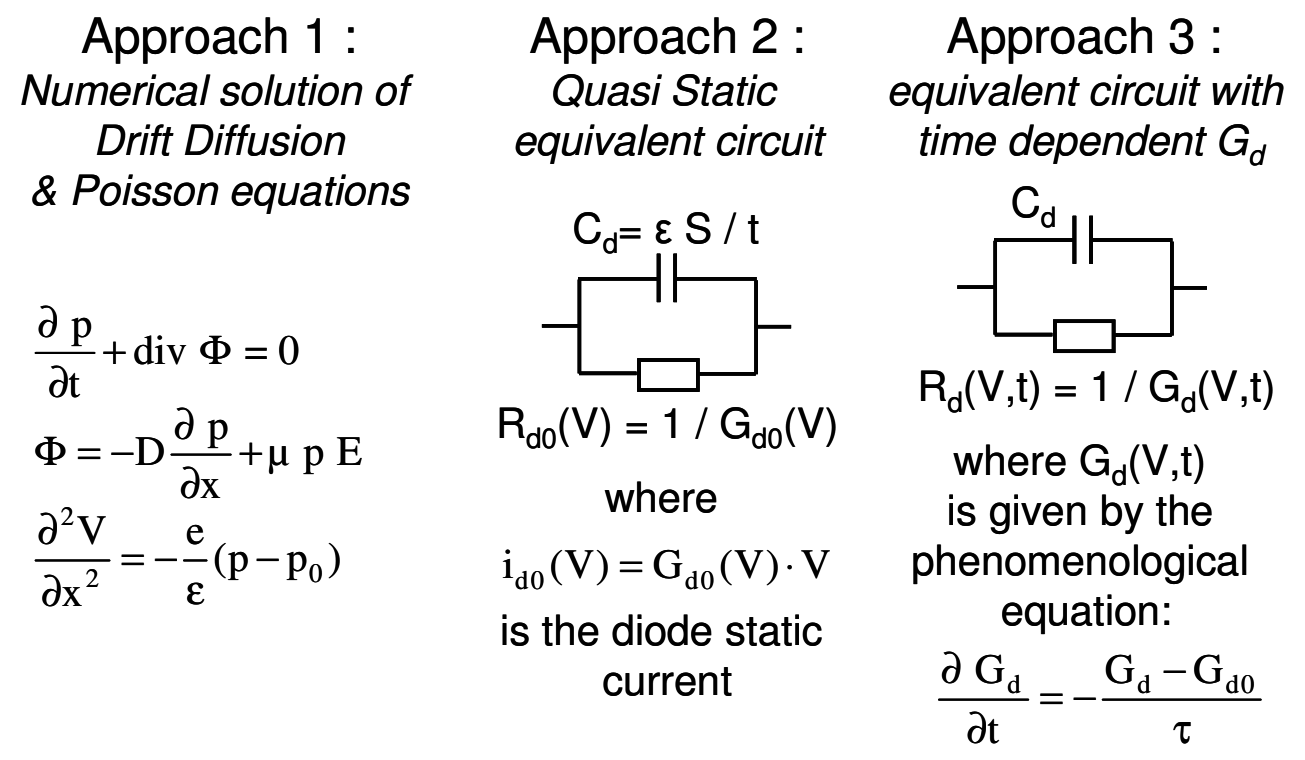

Figure 3. The three approaches to model the time dependent operation of the organic diode considered in this work : 1/ time dependent drift diffusion equations coupled with Poisson; 2 / elementary $\mathrm{G}_{\mathrm{d}}, \mathrm{C}_{\mathrm{d} 0}$ static diode model; 3 / improved diode model including carrier response by a phenomenological first order differential equation.

\subsection{Time dependent mixed mode simulations}

The intrinsically non linear nature of the rectifying process prevents to apply any standard small signal approach, increasing the analysis level of complexity, even for the simple circuit of figure 1. For this reason, the diode cannot be simulated alone, but together with the load resistance and 
capacitance, in a time dependent approach. To this aim, the organic diode has been modeled using the drift and diffusion formalism (in the time domain), using the theoretical background discussed in [19]. Moreover, the time dependent drift and diffusion equation have been numerically solved, according the procedure presented in [20]. The diode simulation is coupled with circuit transient simulations, as illustrated in figure 3 (approach 1).

As the diode is planar (see figure 1), the transport of carriers has been modeled using a one dimensional approach (i.e. along the transverse direction). Moreover, due to the nature of the metallic contacts used in this work, these diodes are essentially unipolar devices, operating only with holes (electrons transport can be ignored). The time dependent operation of the diode is modeled by solving the following set of equations, composed of the continuity equation, coupled with the Poisson equation:

$\mathrm{e} \frac{\partial \mathrm{p}}{\partial \mathrm{t}}+\frac{\partial \mathrm{j}_{\mathrm{p}}}{\partial \mathrm{x}}=0$ with: $\mathrm{j}_{\mathrm{p}}=-\mathrm{e} \mathrm{D}_{\mathrm{p}} \frac{\partial \mathrm{p}}{\partial \mathrm{x}}-\mathrm{e} \mu_{\mathrm{p}} \mathrm{p} \frac{\partial \mathrm{V}}{\partial \mathrm{x}}$

where e is the elementary positive hole charge, $p(x, t)$ the hole concentration, $j_{p}(x, t)$ the hole current density, $V(x, t)$ the electrostatic potential, $\mu_{p}$ (resp. $\left.D_{p}\right)$ the hole mobility (resp. diffusion coefficient). For the sake of simplicity, the Einstein relation $D_{p}=\left(k_{b} T / e\right) \mu_{p}$, where $k_{b}$ is the Boltzmann constant and $\mathrm{T}$ the temperature, is supposed to apply. The electrostatic potential $\mathrm{V}$ is calculated solving self consistently the Poisson Equation (using a Newton algorithm) :

$$
\frac{\partial^{2} \mathrm{~V}}{\partial \mathrm{x}^{2}}=-\frac{\mathrm{e}\left(\mathrm{p}-\mathrm{p}_{0}\right)}{\varepsilon}
$$

where $\varepsilon$ represents the dielectric constant of the organic semiconductor, $\mathrm{p}_{0}$, the equilibrium hole concentration.

The conventional "Schottky type" boundary conditions have been used, leading to :

$$
\mathrm{V}(0)=\Delta \Phi_{1} / \mathrm{e} \text { and } \mathrm{V}(\mathrm{L})=\mathrm{V}_{\mathrm{a}}+\Delta \Phi_{2} / \mathrm{e}
$$


$\mathrm{p}(0)=\mathrm{p}_{0} \exp \left(-\frac{\Delta \Phi_{1}}{\mathrm{k}_{\mathrm{b}} \mathrm{T}}\right)$ and $\mathrm{p}(\mathrm{L})=\mathrm{p}_{0} \exp \left(-\frac{\Delta \Phi_{2}}{\mathrm{k}_{\mathrm{b}} \mathrm{T}}\right)$

where $\mathrm{L}$ represents the diode organic semiconductor thickness, $\mathrm{V}_{\mathrm{a}}$ the bias applied to the junction, and $\Delta \Phi_{1}$ (resp. $\Delta \Phi_{2}$ ) the work function difference between the bottom (resp. top) electrode and the organic semiconductor. Finally, the applied voltage $V_{a}$ is related to the input voltage $V_{\text {in }}=V_{0}$ $\sin (\omega \mathrm{t})$ and the output voltage $\mathrm{V}_{\text {out }}$ by the following set of equations :

$$
\begin{aligned}
& V_{a}(t)=V_{\text {out }}(t)-V_{\text {in }}(t) \\
& C \frac{d V_{\text {out }}}{d t}+\frac{V_{\text {out }}}{R}=i_{d}\left(V_{\text {out }}(t)-V_{\text {in }}(t), t\right)
\end{aligned}
$$

where C (resp. R) are the external capacitance (resp. resistance) of the rectifying circuit, and $i_{d}=S$ $\mathrm{j}_{\mathrm{p}}(\mathrm{L}, \mathrm{t})$ the current flowing through the diode.

As the discrete time step $\Delta \mathrm{t}$ has to be much lower than the input signal period $2 \pi / \omega$, these simulations may become excessively time-consuming in the high frequency regime. For this reasons, a simplified model has been proposed in the following section.

\subsection{Simplified model based on the equivalent circuit model $\mathrm{G}_{\underline{d}}, \mathrm{C}_{\underline{d}}$}

In an attempt to understand better the rectifying circuit operation and to reduce computational time, alternative approaches have been also investigated (represented by approaches 2 and 3 in Fig. 3). The first simplified method (approach 2) consists in replacing the diode by a $G_{d 0}, C_{d}$ equivalent circuit, where $G_{\mathrm{d} 0}$ is voltage dependent equivalent static conductance, and deduced from the static $\mathrm{i}_{\mathrm{d} 0}\left(\mathrm{~V}_{\mathrm{a}}\right)$ characteristic and $\mathrm{C}_{\mathrm{d}}$ represents the geometrical capacitance. This equivalent conductance can be defined by :

$$
\mathrm{G}_{\mathrm{d} 0}\left(\mathrm{~V}_{\mathrm{a}}\right)=\frac{\mathrm{i}_{\mathrm{d} 0}\left(\mathrm{~V}_{\mathrm{a}}\right)}{\mathrm{V}_{\mathrm{a}}}
$$

While this approach is in good agreement with approach 1 at low frequency, it however fails to model the output signal around cut off, as seen in figure 4. This observation demonstrates that the 
frequency response of the static diode capacitance cannot be simply captured by an equivalent circuit model composed of a (time independent) capacitance $\mathrm{C}_{\mathrm{d}}$ and conductance $\mathrm{G}_{\mathrm{d} 0}$, as however assumed in [11] and [12].

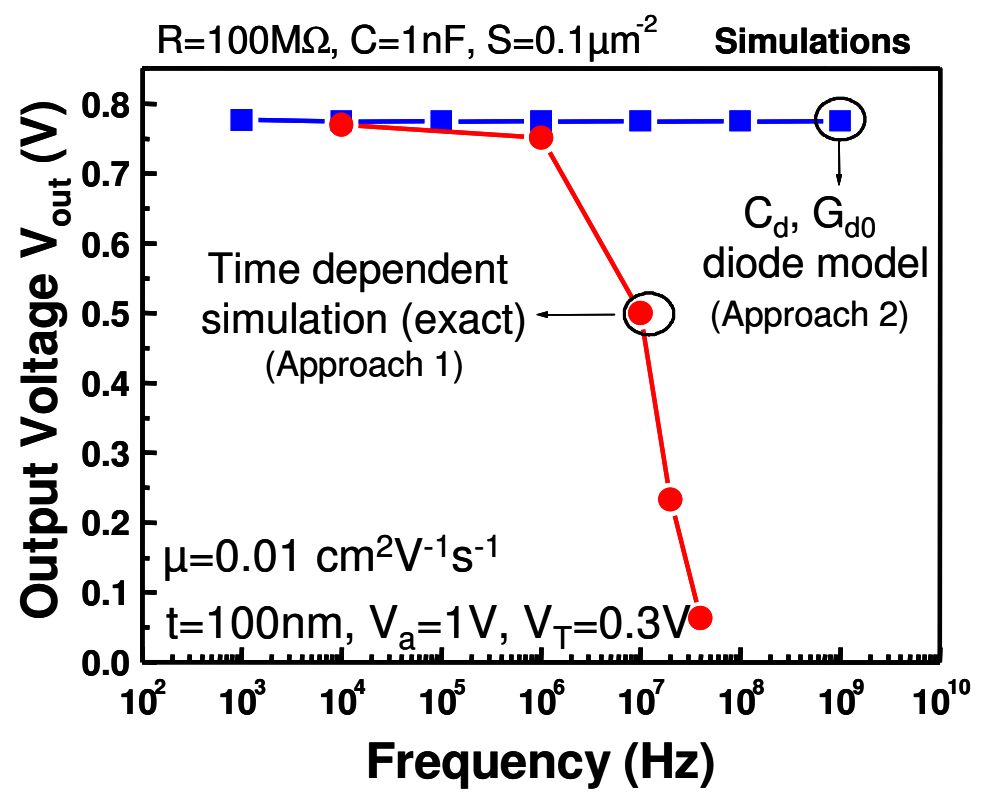

Figure 4 : Calculated average output voltage $\mathrm{V}_{\text {out }}(\mathrm{t})$ of the rectifying circuit versus input signal frequency, using rigorous numerical simulation (approach 1) or simple diode model neglecting carrier response transit time (approach 2). This figure shows that the approach 2, correct in the low frequency regime, fails to capture the cut off at high frequency.

Actually, the fact that the geometrical capacitance of the diode (or by extension any kind of capacitance) cannot cause the frequency cutoff could have been foreseen. Indeed, if we consider the circuit labeled "approach 2" in figure 3, the following time dependent equation can be easily deduced:

$\mathrm{i}_{\mathrm{d} 0}\left(\mathrm{~V}_{\text {in }}-\mathrm{V}_{\text {out }}\right)+\mathrm{C}_{\mathrm{d}} \frac{\mathrm{d}\left(\mathrm{V}_{\text {out }}-\mathrm{V}_{\text {in }}\right)}{\mathrm{dt}}=\mathrm{C} \frac{\mathrm{d} \mathrm{V}_{\text {out }}}{\mathrm{dt}}+\frac{\mathrm{V}_{\text {out }}}{\mathrm{R}}$

By integrating equation (8) over one full period of the input signal $\mathrm{T}=2 \pi / \omega$, we get:

$$
\int_{t}^{t+T}\left(i_{d 0}(t)+C_{d} \frac{d\left(V_{\text {in }}-V_{\text {out }}\right)}{d t}\right) d t=\int_{t}^{t+T}\left(C \frac{\mathrm{dV}_{\text {out }}}{d t}+\frac{V_{\text {out }}}{R}\right) d t
$$


Once the stationary regime of the rectifying diode is achieved, $\mathrm{V}_{\text {out }}(\mathrm{t})$ becomes constant (Note that this is also true in the high frequency regime, where the amplitude of $\mathrm{V}_{\text {out }}$ is almost zero). In this case, both $\mathrm{V}_{\text {in }}$ and $\mathrm{V}_{\text {out }}$ are periodic signal, and thus:

$$
\int_{\mathrm{t}}^{\mathrm{t}+\mathrm{T}}\left(\frac{\mathrm{d}\left(\mathrm{V}_{\text {in }}-\mathrm{V}_{\text {out }}\right)}{\mathrm{dt}}\right) \mathrm{dt}=\mathrm{V}_{\text {in }}(\mathrm{t}+\mathrm{T})-\mathrm{V}_{\text {out }}(\mathrm{t}+\mathrm{T})-\left(\mathrm{V}_{\text {in }}(\mathrm{t})-\mathrm{V}_{\text {out }}(\mathrm{t})\right)=0
$$

In consequence, in the stationary regime, the output voltage $\mathrm{V}_{\text {out }}$ is given by the following equation:

$$
\mathrm{V}_{\text {out }}=\frac{\mathrm{R}}{\mathrm{T}} \int_{\mathrm{t}}^{\mathrm{t}+\mathrm{T}} \mathrm{i}_{\mathrm{d} 0} \mathrm{dt}
$$

Equation (11) shows that, once stabilized, the output voltage $\mathrm{V}_{\text {out }}$ only depend on static parameters $\left(\mathrm{id}_{0}, \mathrm{R}, \mathrm{T} \ldots\right.$...). In particular, it becomes independent of the geometrical capacitance. Consequently, the drastic drop of $\mathrm{V}_{\text {out }}$ observed in the high frequency regime cannot be induced by the diode geometrical capacitance.

\subsection{Simplified model based on the finite carrier response time}

The diode time response appears rather limited by an intrinsic phenomenon, as shown by a closer look at the time evolution of the hole concentration in the middle of the diode (see figure 5). At low frequency, it oscillates from its lowest static value (corresponding to the static hole concentration with a bias of $-\mathrm{V}_{0}$ ) to its highest static value (corresponding to a bias of $+\mathrm{V}_{0}$ ), following the frequency of the input signal. Below the cut off frequency however, the hole concentration remains constant, suggesting that the hole concentration fails to follow the input signal. Obviously, the hole concentration is connected to the equivalent conductance, as detailed in the appendix 1, suggesting that the time response of the hole concentration will also impact the equivalent conductance. 


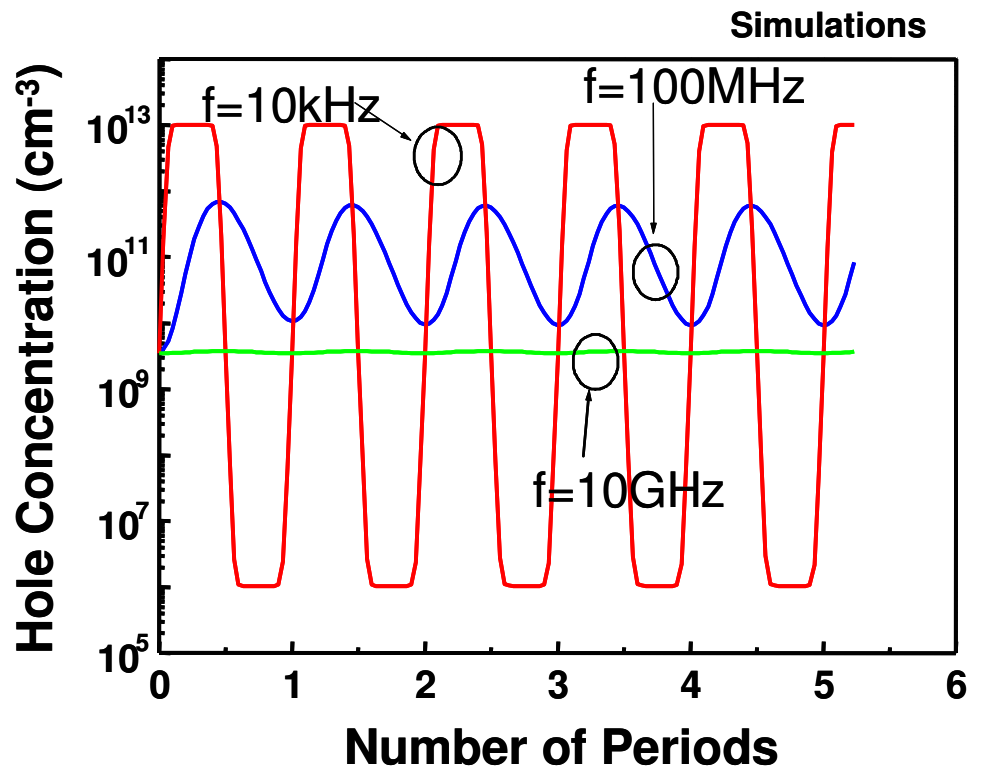

Figure 5: Carrier concentration versus time in the middle of the organic layer, at three input signal frequencies, confirming the role of carrier response time in diode frequency behaviour. ( $\left.\mathrm{t}=100 \mathrm{~nm}, \mu=10^{-2} \mathrm{~cm}^{2} \cdot \mathrm{V}^{-1} \cdot \mathrm{s}^{-1}, \Delta \Phi_{1}=0 \mathrm{eV}, \Delta \Phi_{2}=0,42 \mathrm{eV}, \mathrm{N}_{\mathrm{a}}=10^{13} \mathrm{~cm}^{-3}, \mathrm{~V}_{\mathrm{a}}=1 \mathrm{~V}\right)$

The previous approach 2 has thus been modified by introducing a characteristic response time to the equivalent diode conductance $G_{d}$. Indeed, in the preceding case, the conductance $G_{d}$ was supposed to remain equal to the static conductance $\mathrm{G}_{\mathrm{d} 0}(\mathrm{~V})$. In fact, this approximation implicitly assumes an instantaneous response of the conductance to the applied signal $\mathrm{V}_{\text {in }}(\mathrm{t})-\mathrm{V}_{\text {out }}(\mathrm{t})$. In the new approach, the conductance has been modeled by a time dependent function $G_{d}(V, t)$, responding to the applied signal with a characteristic delay time $\tau$. The dynamic of this response has been empirically modeled in the simplest possible way, i.e. by the following first order differential equation:

$$
\frac{\partial \mathrm{G}_{\mathrm{d}}(\mathrm{V})}{\partial \mathrm{t}}=\frac{\mathrm{G}_{\mathrm{d}}(\mathrm{V})-\mathrm{G}_{\mathrm{d} 0}(\mathrm{~V})}{\tau}
$$

The next step consists in determining the characteristic delay time $\tau$. As detailed in the second appendix, analytical calculations suggest that a good approximation of this characteristic time constant in this unipolar device is proportional to the carrier time-of-flight, given by : 


$$
\tau=\alpha \frac{\mathrm{L}^{2}}{\mu_{\mathrm{p}}\left(\mathrm{V}_{\mathrm{a}}-\mathrm{V}_{\mathrm{T}}\right)}
$$

Comparisons with numerical simulations of rectifying circuits (approach 1) suggest taking the coefficient $\alpha$ equal to 0.82 . The validity of this model (approach 3) will be investigated in details in the next section. 


\section{Results and discussion}

4.1. Comparison between the "mixed mode" simulations (approach 1) and simplified model (approach 3)
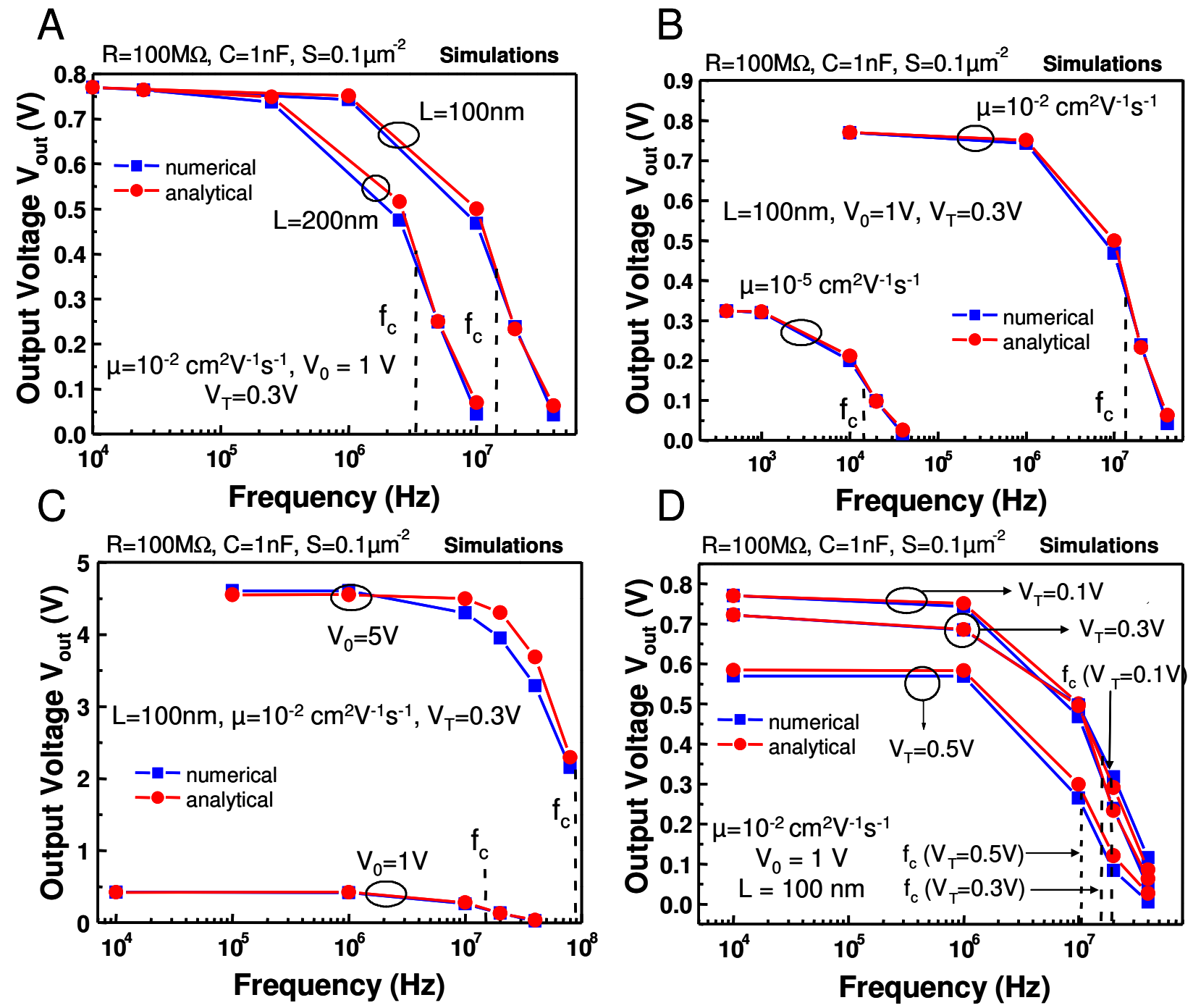

Figure 6. Calculated average output voltage $\mathrm{V}_{\text {out }}$ using approach 1 (full numerical solution) and approach 3 (Equivalent circuit model with time dependant conductance $G_{d}\left(V_{a}, t\right)$ of the rectifying circuit versus input signal frequency, for different parameters. Plot A : for two different semiconductor thickness $\mathrm{L}=100 \mathrm{~nm}$ and $200 \mathrm{~nm}$; Plot B : for two different mobilities $\mu=10^{-2}$ $\mathrm{cm}^{2} \cdot \mathrm{V}^{-1} \cdot \mathrm{s}^{-1}$ and $\mu=10^{-5} \mathrm{~cm}^{2} \cdot \mathrm{V}^{-1} \cdot \mathrm{s}^{-1}$; Plot $\mathrm{C}$ : for two different amplitudes of $\mathrm{V}_{\text {in }} 1 \mathrm{~V}$ and $5 \mathrm{~V}$, Plot $\mathrm{D}$ : for three different threshold voltages $0.1 \mathrm{~V}, 0.3 \mathrm{~V}, 0.5 \mathrm{~V}$. In absence of any other indications, the parameters by defaults in the simulation are : $\mathrm{L}=100 \mathrm{~nm}, \mathrm{p}_{0}=3.310^{14} \mathrm{~cm}^{-3}, \mu=10^{-2} \mathrm{~cm}^{2} \cdot \mathrm{V}^{-1} \cdot \mathrm{s}^{-1}, \mathrm{~V}_{\text {in }}$ amplitude $=1 \mathrm{~V}$, and $\mathrm{V}_{\mathrm{T}}=0.3 \mathrm{~V}$. 
The exact "mixed mode" approach 1 and the approximated approach have been extensively compared, in order to investigate its validity. Simulation of the output voltage versus input signal frequency have been performed, changing the semiconductor thickness $L$, the hole mobility $\mu_{\mathrm{p}}$, the amplitude of the input signal $\mathrm{V}_{0}$ and the diode threshold voltage $\mathrm{V}_{\mathrm{T}}$. Results have been plotted in Figure 6. It turns out that the approximated simulations are in very good agreement with the full numerical ones, in all the devices investigated. This observation confirms that: $1 /$ the $C_{d}, G_{d}$ equivalent circuit model fits very well the static operation of the diode in the low frequency range, 2 / the time-of-flight is very much representative of the diode characteristic response time $\tau, 3 /$ the first order differential equation (12) provides a very good phenomenological description of the equivalent conductance versus time. In the following, the approach 3, much more numerically efficient, will be used to simulate the rectifying circuit.

\subsection{Comparison with experiments}

Simulations have been compared with experiments performed on the polymer diodes presented in the first section. First of all, basic parameters such as mobility, equilibrium hole concentration, and work functions have been extracted by comparison by fitting the static I-V characteristic of diodes of several thicknesses, realized using the same process. At low voltages, to reproduce the static current below threshold, it has been needed to account for shallow traps (i.e. taking into account the trapping and de-trapping of holes in the Poisson equation, following the Lampert model [21]). Interestingly, all the extracted parameters (see table 1) have been found, as expected, almost independent of the diode thickness. Sample using a second organic polymer, the PCBTDPP introduced in [22], has also been processed, in order to compare experiment and simulations one sample featuring different mobilities.

Using parameters extracted in the static regime (table 1), as seen in figure 8, experimental output voltage versus frequency curves have been nicely reproduced by simulations, without introducing any other fitting parameters. This result confirms that the present model captures nicely the time 
performance of devices featuring different thicknesses (figure 8) as well as different mobility (figure 9). It thus confirms the validity of the "time-of-flight" formula used in the third approach, and in particular its $\mathrm{L}^{2}$ and $\mu^{-1}$ dependency. At last, as already seen in figure 2 , note that rectification at $13.56 \mathrm{MHz}$ has been achieved using the thinnest diode $(\mathrm{t}=70 \mathrm{~nm})$, despite the relatively low mobility $0.01 \mathrm{~cm}^{2} \mathrm{~V}^{-1} \mathrm{~s}^{-1}$ of the spin coated amorphous polymers TFB material.

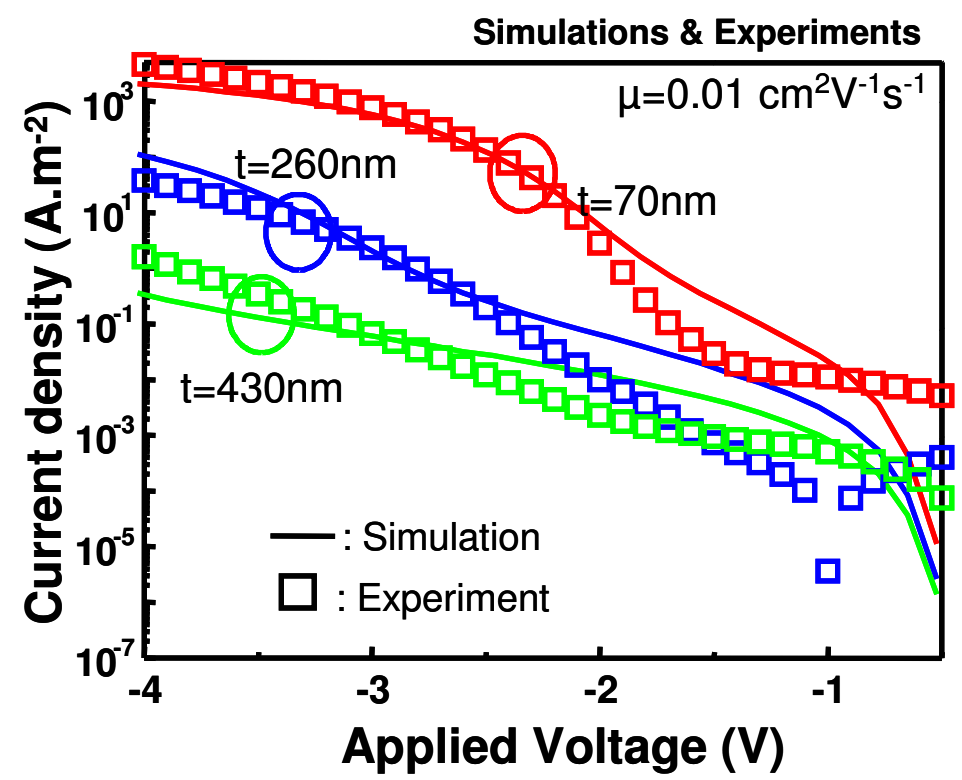

Figure 7. Static I-V characteristic of the TFB organic diode in direct regime, and corresponding simulations (using approach 1) (the reverse current, lower than the measurement set up resolution, has not been shown).

\begin{tabular}{|c|c|c|c|}
\hline Samples & $\begin{array}{c}\text { TFB } \\
\mathrm{L}=70 \mathrm{~nm}\end{array}$ & $\begin{array}{c}\text { TFB } \\
\mathrm{L}=260 \mathrm{~nm}\end{array}$ & $\begin{array}{c}\text { TFB } \\
\mathrm{L}=430 \mathrm{~nm}\end{array}$ \\
\hline $\begin{array}{c}\text { Trap } \\
\text { Concentration } \mathrm{N}_{\mathrm{t}}\left(\mathrm{cm}^{-3}\right)\end{array}$ & $1.410^{17}$ & $1.510^{16}$ & $1.010^{16}$ \\
\hline $\begin{array}{c}\text { Doping } \\
\text { Concentration } \mathrm{N}_{\mathrm{a}}\left(\mathrm{cm}^{-3}\right)\end{array}$ & $10^{12}$ & $10^{12}$ & $10^{12}$ \\
\hline $\begin{array}{c}\text { Hole Concentration } \\
\text { at injecting contact }\left(\mathrm{cm}^{-3}\right)\end{array}$ & $6.910^{14}$ & $6.910^{14}$ & $6.910^{14}$ \\
\hline Mobility $\left(\mathrm{cm}^{2} \cdot \mathrm{V}^{-1} \cdot \mathrm{s}^{-1)}\right.$ & 0.01 & 0.01 & 0.01 \\
\hline $\begin{array}{c}\text { Work function } \\
\text { Difference between the } \\
\text { two contacts }(\mathrm{eV})\end{array}$ & 0.97 & 0.97 & 0.97 \\
\hline
\end{tabular}

Table 1. Parameters used to fit static experiments (figure 7). Mobility, equilibrium hole concentration and work function has been found identical on the three diodes. Only the trap concentration has been found to vary slightly from one sample to another. 


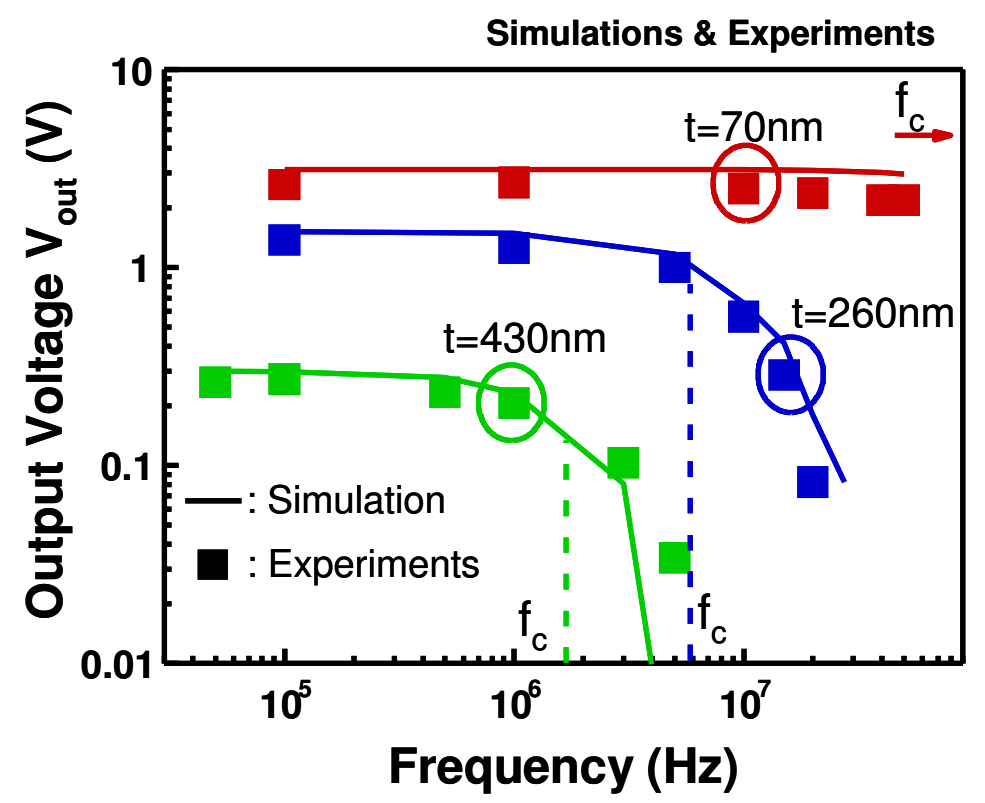

Figure 8: Experimental and calculated average output voltage $\mathrm{V}_{\text {out }}$ versus input signal frequency, for the three diodes, featuring various thicknesses L. Circuit is composed of a TFB diode of area S $=210^{-7} \mathrm{~m}^{2}$, a resistance of $\mathrm{R}=1 \mathrm{M} \Omega$, and a capacitor of $\mathrm{C}=1 \mu \mathrm{F}$. The input signal amplitude is $\mathrm{V}_{0}$ $=6 \mathrm{~V}$.

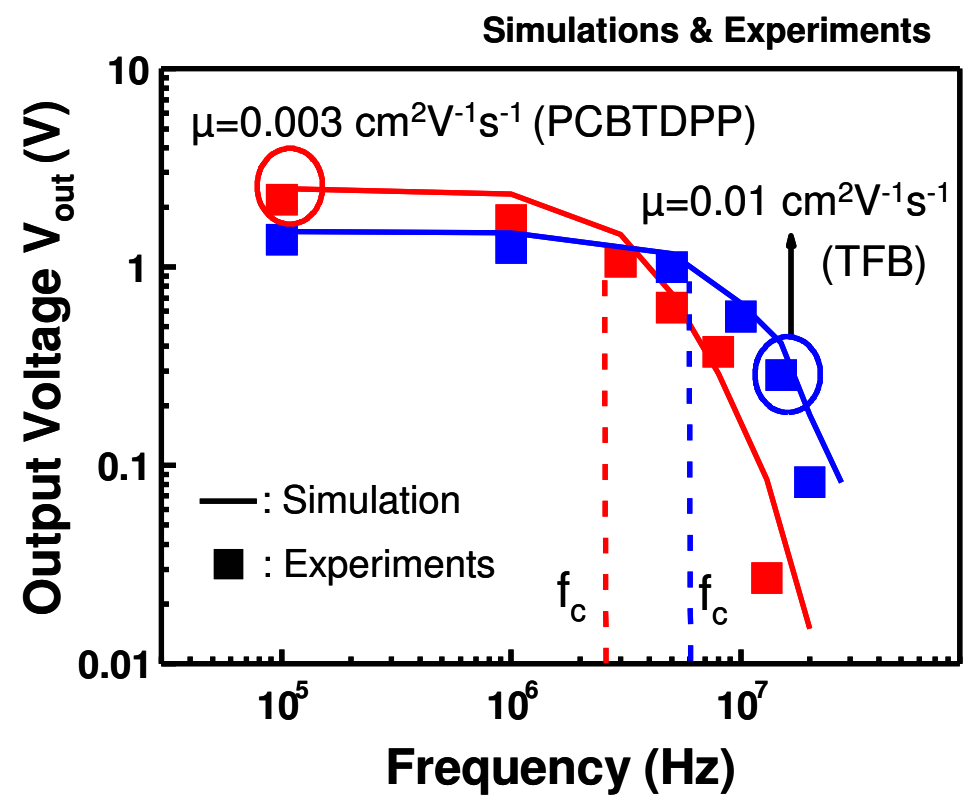

Figure 9. Experimental and calculated average output voltage $\mathrm{V}_{\text {out }}$ versus input signal frequency, for two diodes with different organic semiconductors (TFB and PCBTDPP). Circuit is composed of a diode of area $S=210^{-7} \mathrm{~m}^{2}$, a resistance of $\mathrm{R}=1 \mathrm{M} \Omega$, and a capacitor of $\mathrm{C}=1 \mu \mathrm{F}$. The active layer thickness is $\mathrm{L}=260 \mathrm{~nm}$. The input signal amplitude is $\mathrm{V}_{0}=6 \mathrm{~V}$. 


\subsection{Discussions}

The validity of the "time-of-flight" formula for the cut off frequency has simple consequences, illustrated in figure 10, where the cut off frequency has been plotted versus active layer thickness L, for several mobilities $\mu$. In this plot, the shadowed areas indicate either too low cut off frequency or too thin organic thickness (the limit being arbitrary estimated at $\mathrm{L}>40 \mathrm{~nm}$ ). In order to exceed the minimum frequency value of $13.56 \mathrm{MHz}$, low mobilities $\mu$ of polymer semiconductors, provided that they exceed the minimum value of $10^{-4} \mathrm{~cm}^{2} \mathrm{~V}^{-1} \mathrm{~s}^{-1}$, can be simply compensated by using diodes with ultra thin organic layer $\mathrm{L}$, in order to minimize the ratio $\mathrm{L}^{2} / \mu$. Some of the available experimental data on the cut off frequency versus thicknesses have been also indicated in this figure. These plots suggest that experimental data are consistent with organic mobilities in the $10^{-3}$ $10^{-2} \mathrm{~cm}^{2} \mathrm{~V}^{-1} \mathrm{~s}^{-1}$ range, which is a reasonable conclusion. The reference [5] $\left(\mathrm{f}_{\mathrm{c}}>\right.$ hundreds of megahertz, $\mathrm{L}=160 \mathrm{~nm}$ ) is also in line with the "time-of-flight" theory, as the reported mobility in this work was $0.15 \mathrm{~cm}^{2} \mathrm{~V}^{-1} \mathrm{~s}^{-1}$.

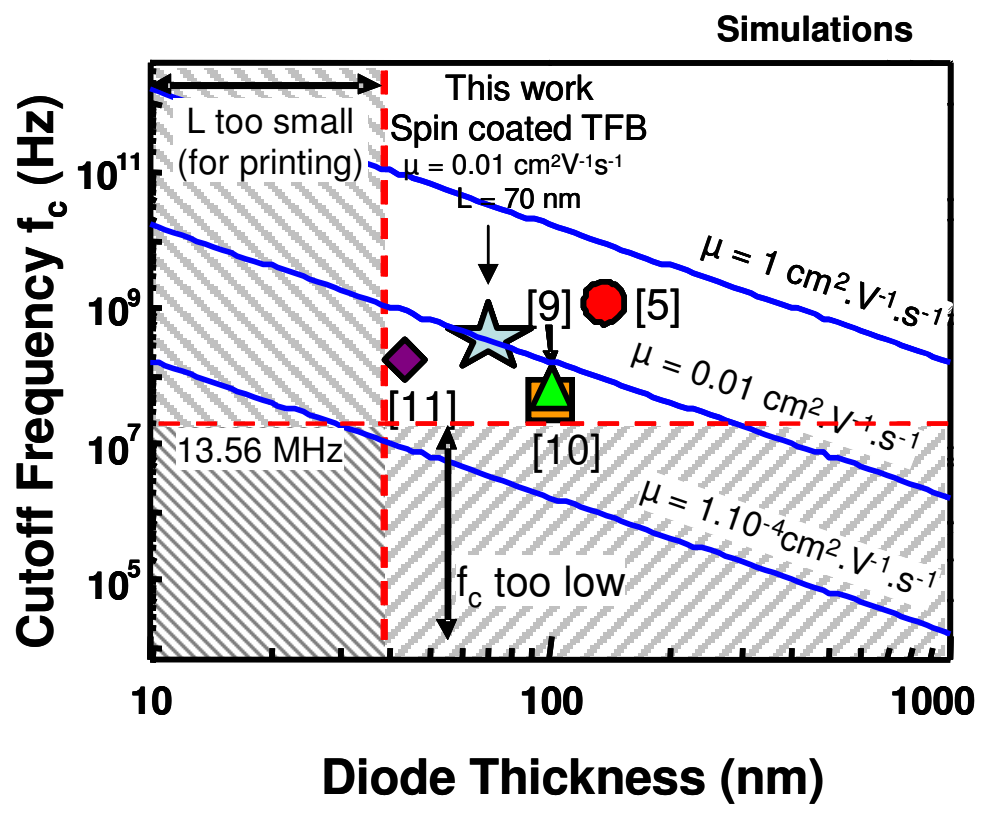

Figure 10. Rectifying circuit cut off frequency versus diode thickness for various organic layer mobilities. Shadowed areas indicate either too low cut off frequency or too thin organic thickness (very difficult to achieve using printing deposition techniques). Some of the literature performances are also reported for comparison. 
As already pointed out in other works such as [12] for instance, our simulations (not shown here) confirm that a ratio between the forward and reverse currents of two orders of magnitude is sufficient to achieve an efficient rectification. Interestingly, the time-of-flight formula even suggests that it is not desirable to further increase this ratio. Indeed, higher ratio would require a higher threshold voltage, which would degrade the cut off frequency $f_{c}=\mu\left(V_{A}-V_{T}\right) / L^{2}$.

Finally, note that the measurement of the cut off frequency is also an easy way to extract the carrier mobility. This method allows a measurement of the diode equivalent conductance cut off frequency independently of the equivalent capacitance, which can be very useful. Indeed, a direct measurement of the diode conductance by measuring its admittance $\mathrm{Y}$, given by :

$\mathrm{Y}=\mathrm{G}_{\mathrm{d}}\left(\omega, \mathrm{V}_{\mathrm{a}}\right)+\mathrm{i} \omega \mathrm{C}_{\mathrm{d}}\left(\omega, \mathrm{V}_{\mathrm{a}}\right)$

requires that the equivalent conductance $G_{d}$ is not negligible compare to $\omega C_{d}$. This condition, which may be difficult to achieve at high frequency, is however not needed in the rectifying circuit configuration.

\section{Conclusions}

The frequency response of unipolar organic Schottky diodes used in a rectifying circuit, such as the one needed in RFID tag for instance, has been investigated in details.

First of all, the time dependent response of rectifying circuits has been simulated solving both the Drift Diffusion and Poisson equations to model the hole transport within the diode, together with the time dependent circuit equations. Several schemes of approximation have also been considered. The first one consists in replacing the diode by its static, voltage dependent, $G_{d 0}, C_{d}$ equivalent circuit. Valid in the low frequency regime, this approach however fails to capture the performance degradation obtained at high frequency, showing that the diode equivalent capacitance is not responsible for the rectifying circuit cut off effect. This approach can however be improved by introducing a time dependency to the equivalent conductance, by the means of a first order linear differential equation. The critical delay of the conductance has been found reasonably well captured 
by the carrier time-of-flight, as suggested by analytical calculation presented in appendix 2 and confirmed by extensive comparison with numerical simulations.

Simulations have also been validated by comparison with experiments, featuring diodes with different mobilities and thicknesses.

Finally, this work explains why the $13.56 \mathrm{MHz}$ frequency can be achieved using polymer organic semiconductors, as already experimentally demonstrated in the literature, compensating the poor value of polymer mobility by the ultra thin thickness of the diode active layer.

\section{Appendix 1 : equivalent conductance $G_{d}$ of the organic diode}

In this appendix, a simple expression of the equivalent conductance model for the organic diode is derived. It can be used $1 /$ to derive the equivalent conductance in the static regime, $2 /$ to derive approximated time dependent conductance.

Starting from the drift and diffusion current conservation equation:

$\frac{\mathrm{j}_{\mathrm{p}}}{\mathrm{e} \mu_{\mathrm{p}} \mathrm{p}}=-\frac{\mathrm{kT}}{\mathrm{e}} \frac{1}{\mathrm{p}} \frac{\partial \mathrm{p}}{\partial \mathrm{x}}-\frac{\partial \mathrm{V}}{\partial \mathrm{x}}$

We take the integral on the full semiconductor layer, leading to:

$\int_{0}^{\mathrm{L}} \frac{\mathrm{j}_{\mathrm{p}}}{\mathrm{e} \mu_{\mathrm{p}} \mathrm{p}} \mathrm{dx}=-\frac{\mathrm{kT}}{\mathrm{e}} \int_{0}^{\mathrm{L}} \frac{1}{\mathrm{p}} \frac{\partial \mathrm{p}}{\partial \mathrm{x}} \mathrm{dx}-(\mathrm{V}(0)-\mathrm{V}(\mathrm{L}))$

The previous equation can be simplified as :

$\int_{0}^{\mathrm{L}} \frac{\mathrm{j}_{\mathrm{p}}}{\mathrm{e} \mu_{\mathrm{p}} \mathrm{p}} \mathrm{dx}=-\frac{\mathrm{kT}}{\mathrm{e}} \ln \frac{\mathrm{p}(\mathrm{L})}{\mathrm{p}(0)}+\mathrm{V}_{\mathrm{a}}-\left(\Delta \Phi_{2}-\Delta \Phi_{1}\right) / \mathrm{e}$

The boundary conditions on the hole concentration imply:

$\frac{\mathrm{p}(\mathrm{L})}{\mathrm{p}(0)}=\exp \left(-\frac{\Delta \Phi_{2}-\Delta \Phi_{1}}{\mathrm{k}_{\mathrm{b}} \mathrm{T}}\right)$

In consequences, current density and applied voltage are connected by the following equation : 
$\int_{0}^{\mathrm{L}} \frac{\mathrm{j}_{\mathrm{p}}(\mathrm{x}, \mathrm{t})}{\mathrm{e} \mu_{\mathrm{p}} \mathrm{p}(\mathrm{x}, \mathrm{t})} \mathrm{dx}=\mathrm{V}_{\mathrm{a}}$

In the static regime, the current density $\mathrm{j}_{\mathrm{p}}$ is uniform (current conservation), and thus the static conductance is exactly given by:

$$
G_{d 0}=\frac{j_{p} S}{V_{a}}=S \times \int_{0}^{L} \frac{1}{e \mu_{p} p(x)} d x
$$

where $S$ is the diode area. Interestingly, although this equation seems to account only for drift and not diffusion, it includes however, as previously proved, both mechanisms (providing to use the exact $\mathrm{p}(\mathrm{x})$ profile). Moreover, note that $\mathrm{G}_{\mathrm{d} 0}$ depends on the applied voltage $\mathrm{V}_{\mathrm{a}}$ through $\mathrm{p}(\mathrm{x})$.

By extension of this previous static equation, in the next appendix, the time evolution of the conductance will be approximated by the following equation:

$$
\mathrm{G}_{\mathrm{d}}\left(\mathrm{V}_{\mathrm{a}}, \mathrm{t}\right) \approx \mathrm{S} \times \int_{0}^{\mathrm{L}} \frac{1}{\mathrm{e} \mu_{\mathrm{p}} \mathrm{p}(\mathrm{x}, \mathrm{t})} \mathrm{dx}
$$

\section{Appendix 2: Majority carrier response time}

In the following appendix, a procedure to calculate the majority carrier response time within the organic diode has been proposed. To this aim, the following simplifying assumptions have been made. First of all, the electric field $\mathrm{E}$ has been assumed constant in the diode. This approximation is strictly valid only in ultra thin low doped semiconductor layers.

$$
\mathrm{E}=\frac{\mathrm{V}_{\mathrm{a}}-\mathrm{V}_{\mathrm{T}}}{\mathrm{L}}
$$

where $V_{a}$ represents the applied bias on the diode and $V_{T}$, an empirical threshold voltage. In absence of traps, this threshold voltage is simply given by the built in potential $\left(\Delta \Phi_{2}-\Delta \Phi_{1}\right) / \mathrm{e}$. In all case, it can be extracted using the semilogarithmic plot of the static I-V curve, and its value is equal to the voltage at which the I-V curve, in the forward regime, is not an exponential anymore. 
We found the threshold voltage to be equal to $3 \mathrm{~V}, 4 \mathrm{~V}$ and $5 \mathrm{~V}$ for the devices thicknesses of 70 $\mathrm{nm}, 260 \mathrm{~nm}$ and $430 \mathrm{~nm}$ respectively.

The value of this characteristic time can then be approximately estimated by solving the continuity equation when a Heaviside signal is applied to the diode at $\mathrm{t}=0$. The diffusion mechanism, essentially operating around $\mathrm{V}_{\mathrm{a}} \sim \mathrm{V}_{\mathrm{T}}$, has been neglected for sake of simplicity. The continuity equation then becomes:

$\frac{\partial p}{\partial t}+\mu_{p} E \frac{\partial p}{\partial x}=0$

To solve this equation, the unilateral Laplace transform $\mathrm{P}(\mathrm{x}, \mathrm{s})$ of the carrier concentration $\mathrm{p}(\mathrm{x}, \mathrm{t})$ has been used, leading to:

$s \mathrm{P}-\mathrm{p}(\mathrm{x}, 0)+\mu_{\mathrm{p}} \mathrm{E} \frac{\partial \mathrm{P}}{\partial \mathrm{x}}=0$

At $\mathrm{t}=0$, the diode was supposed to be at thermal equilibrium, with no applied voltage. In consequences, the initial hole profile $\mathrm{p}(\mathrm{x}, \mathrm{t}=0)$ is given by:

$\mathrm{p}(\mathrm{x}, \mathrm{t}=0)=\mathrm{p}_{\mathrm{c} 0} \times \exp \left(-\frac{\mathrm{e}\left(\Delta \Phi_{2}-\Delta \Phi_{1}\right)}{\mathrm{kT} \mathrm{L}} \mathrm{x}\right)$

where $\mathrm{p}_{\mathrm{c} 0}$ is the fixed boundary condition given by equation (4). The solution of (24) is:

$P(x, s)=A \exp \left(-\frac{s x}{\mu E}\right)+g(x)$

where $\mathrm{A}$ is an integration constant and $\mathrm{g}$ a particular solution, given by:

$$
\mathrm{g}(\mathrm{x})=\frac{\mathrm{p}_{\mathrm{c} 0}}{\mathrm{~s}-\mu \mathrm{E} \frac{\mathrm{e}\left(\Delta \Phi_{2}-\Delta \Phi_{1}\right)}{\mathrm{kT} \mathrm{L}}} \exp \left(-\frac{\mathrm{e}\left(\Delta \Phi_{2}-\Delta \Phi_{1}\right)}{\mathrm{kT} \mathrm{L}} \mathrm{x}\right)
$$

The application of the boundary condition at $\mathrm{x}=0$ leads to:

$$
P(x=0, s)=A+\frac{p_{c 0}}{s-\mu E \frac{e\left(\Delta \Phi_{2}-\Delta \Phi_{1}\right)}{k T L}}=\int_{0}^{\infty} e^{-s t} p(x=0, t) d t=\frac{p_{c 0}}{s}
$$

The later equation can be used to find the integration constant A, leading to: 


$$
\mathrm{A}=\mathrm{p}_{\mathrm{c} 0}\left(\mathrm{~s}^{-1}-\left(\mathrm{s}-\mu \mathrm{E} \frac{\mathrm{e}\left(\Delta \Phi_{2}-\Delta \Phi_{1}\right)}{\mathrm{kT} \mathrm{L}}\right)^{-1}\right)
$$

Finally P can be written as follows:

$$
\mathrm{P}(\mathrm{x}, \mathrm{s})=\left(\frac{\mathrm{p}_{\mathrm{c} 0}}{\mathrm{~s}} \exp \left(-\frac{\mathrm{s} \mathrm{x}}{\mu \mathrm{E}}\right)+\frac{\mathrm{p}_{\mathrm{c} 0}}{\mathrm{~s}-\mu \mathrm{E} \frac{\mathrm{e}\left(\Delta \Phi_{2}-\Delta \Phi_{1}\right)}{\mathrm{kTL}}}\left(\exp \left(-\frac{\mathrm{e}\left(\Delta \Phi_{2}-\Delta \Phi_{1}\right)}{\mathrm{kTL}} \mathrm{x}\right)-\exp \left(-\frac{\mathrm{s} \mathrm{x}}{\mu \mathrm{E}}\right)\right)\right)
$$

In order to calculate the inverse Laplace transform of $\mathrm{P}$, we have used the following usual formula:

$$
\begin{aligned}
& \frac{\exp (-\tau \mathrm{s})}{\mathrm{s}} \rightarrow(\mathrm{t}>\tau) \\
& \frac{1}{\mathrm{~s}+\alpha} \rightarrow \exp (-\alpha \mathrm{t})(\mathrm{t}>0) \\
& \frac{\exp (-\tau \mathrm{s})}{(\mathrm{s}+\mathrm{a})^{\mathrm{n}+1}} \rightarrow \frac{(\mathrm{t}-\tau)^{\mathrm{n}}}{\mathrm{n} !} \exp (-\mathrm{a}(\mathrm{t}-\tau)) \quad(\mathrm{t}>\tau)
\end{aligned}
$$

And the inverse Laplace Transform of $\mathrm{p}(\mathrm{x}, \mathrm{s})$ can then be calculated:

$$
\mathrm{p}(\mathrm{x}, \mathrm{t})=\mathrm{p}_{\mathrm{c} 0} \times\left[\exp \left(\frac{\mathrm{e}\left(\Delta \Phi_{2}-\Delta \Phi_{1}\right)}{\mathrm{kT} \mathrm{L}}(\mathrm{L}-\mu \mathrm{Et})\right)\right] \times\left[\left(\mathrm{t}-\frac{\mathrm{x}}{\mu \mathrm{E}}\right)<0\right]+\mathrm{p}_{\mathrm{c} 0} \times\left[\left(\mathrm{t}-\frac{\mathrm{x}}{\mu \mathrm{E}}\right)>0\right]
$$

Knowing the hole concentration, the conductance $G_{d}$ can then be approximated by (see appendix 1 for details):

$$
\mathrm{G}_{\mathrm{d}}\left(\mathrm{V}_{\mathrm{a}}, \mathrm{t}\right) \approx \mathrm{S} \times \int_{0}^{\mathrm{L}} \frac{1}{\mathrm{e} \mu_{\mathrm{p}} \mathrm{p}(\mathrm{x}, \mathrm{t})} \mathrm{dx}
$$

After calculations we find:

$$
\mathrm{G}_{\mathrm{d}}=\frac{\mathrm{Se \mu} \mathrm{p}_{\mathrm{c} 0}}{\left[\mu \mathrm{E} \mathrm{t}+\frac{\mathrm{kTL}\left(\exp \left(\frac{\mathrm{e}\left(\Delta \Phi_{2}-\Delta \Phi_{1}\right)}{\mathrm{kTL}}(\mathrm{L}-\mu \mathrm{Et})\right)-1\right)}{\mathrm{e}\left(\Delta \Phi_{2}-\Delta \Phi_{1}\right)}\right] \times\left(\mathrm{t}<\frac{\mathrm{L}}{\mu \mathrm{E}}\right)+\mathrm{L} \times\left(\mathrm{t}>\frac{\mathrm{L}}{\mu \mathrm{E}}\right)}
$$

We can see in that the expression of the diode conductance will change after a time $\tau_{\mathrm{H}}$ equal to: 


$$
\tau_{\mathrm{H}}=\frac{\mathrm{L}}{\mu \mathrm{E}}=\frac{\mathrm{L}^{2}}{\mu\left(\mathrm{V}_{\mathrm{a}}-\mathrm{V}_{\mathrm{T}}\right)} .
$$




\section{References}

[1] M. Böhm, A. Ullmann, D. Zipperer, A. Knobloch, W.H. Glauert, W. Fix, IEEE International Solid-State Circuits Conference Digest Technical Papers p. 270 -271 (2006).

[2] E. Cantatore, T. C. T. Geuns, G. H. Gelinck, E. van Veenendaal, A. F.A. Gruijthuijsen, L. Schrijnemakers, S. Drews, D. M. de Leeuw, IEEE Jour. Solid-State Circuits, 42, 84 (2007).

[3] A. Ullmann, M. Böhm, J. Krumm, W. Fix, Proceeding of the International Conference on Organic Electronics, p. 53, The Netherlands, 2007, Eindhoven.

[4] R. Blache, J. Krumm, W. Fix, IEEE International Solid-State Circuits Conference Digest Technical Papers, pp. 208-209, (2009).

[5] S. Steudel, K. Myny, V. Arkhipov, C. Deibel, S. D. Vusser, J. Genoe and P. Heremans, Nature Mat. 4, 597 (2005).

[6] K. Myny, S. Steudel, P. Vicca, J. Genoe and P. Heremans, Appl. Phys. Lett. 93, 093305 (2008).

[7] K. Myny, S. Steudel, P. Vicca, M. J. Beenhakkers, N. A. J. M. Van Aerle, G. H. Gelinck, J. Genoe, W. Dehaene, P. Heremans, Solid-State Electron. 53, 1220 (2009).

[8] K. Myny, S. Steudel, S. Smout, P. Vicca, F. Furthner, B. van der Putten, A.K. Tripathi, G.H. Gelinck, J. Genoe, W. Dehaene, P. Heremans, Org. Electron. 11, 1176 (2010).

[9] B. N. Pal, J. Sun, B. J. Jung, E. Choi, A. G. Andreou, H. E. Katz, Adv. Funct. Mater. 20, 1023 (2008).

[10] H. Wang, Z. Ji, L. Shang, X. Liu, Y. Peng and M. Liu, IEEE Electron Device Lett. 31, 506 (2010).

[11] Y. Ai, S. Gowrisanker, H. Jia, I. Trachtenberg, E. Vogel, R. M. Wallace, B. E. Gnade, R. Barnett, H. Stiegler, H. Edwards, Appl. Phys. Lett. 90, 262105 (2007).

[12] L. Ma, J. Ouyang, Y. Yang, Appl. Phys. Lett., 84, 4786 (2004).

[13] R. Rotzoll, S. Mohapatra, V. Olariu, R. Wenz, M. Grigas, and K. Dimmlerb, O. Shchekin, A. Dodabalapur, Appl. Phys. Lett. 88, 123502 (2006).

[14] B. Cobb, Y. T. Jeong, A. Dodabalapur, Appl. Phys. Lett. 92, 103302 (2008).

[15] K. E. Lilja, T. G. Bäcklund, D. Lupo, T. Hassinen, T. Joutsenoja, Org. Electron., 10, 1011 (2009).

[16] M. Jung, J. Kim, J. Noh, N. Lim, C. Lim, G. Lee, J. Kim, H. Kang, K. Jung, A. D. Leonard, J. M. Tour, G. Cho, IEEE Trans. Electron Devices 57, 571 (2010).

[17] C. -Y. Lin, C. -H. Tsai, H. -T. Lin, L. -C. Chang, Y. -H. Yeh, Z. Pei, Y. R. Peng, C. -C. Wua, Org. Electron. 12, 1777 (2011).

[18] J. M. Verilhac, M. Benwadih, S. Altazin, S. Jacob, R. Gwoziecki, R. Coppard and C. Serbutoviez Appl. Phys. Lett. 94, 143301 (2009).

[19] S. Scheinert, G. Paasch, Phys. Status Solidy A 201, 1263 (2004).

[20] S. Selberherr, "Analysis and Simulation of Semiconductor Devices", Springer-Verlag, Wien and New York, (1984).

[21] M. A. Lampert and P. Mark, "Current Injection in Solids", Academic Press, New York. (1970).

[22] Y. Zou, D. Gendron, R. Badrou-Aich, A. Najari, Y. Tao and M. Leclerc, Macromolecules 42, $2891(2009)$ 